Seção Temática: Carreira e Remuneração Docente Volume 9 - 2019|n. 4

\title{
Remuneração de Professores da Educação Básica em Tempos de FUNDEB, PSPN e PNE 2014-2024
}

\author{
Marcos Edgar Bassi \\ Universidade Federal de Santa Catarina, Florianópolis/SC - Brasil \\ Maria Dilnéia Espíndola Fernandes \\ Universidade Federal de Mato Grosso do Sul (UFMS), Campo Grande/MS - Brasil \\ Rosana Maria Gemaque Rolim \\ Universidade Federal do Pará, Belém/PA - Brasil
}

Prezadas leitoras, prezados leitores, este volume da revista Fineduca traz um um conjunto de artigos em torno da temática da remuneração do magistério público da educação básica. Os artigos selecionados são resultado do esforço de pesquisadoras e pesquisadores atentos ao contexto recente das políticas educacionais, que ressaltaram, entre seus temas em pauta, a concretização de uma das mais caras reivindicações do movimento dos trabalhadores em educação'1.

Com efeito, desde que a política de fundos no financiamento da educação básica foi inaugurada com o Fundo de Manutenção e Desenvolvimento do Ensino Fundamental e de Valorização do Magistério (Fundef) em 1996 (BRASIL, 1996), as discussões e ações políticas voltadas à melhora/ampliação da remuneração do magistério da educação básica ganharam relevo como um dos aspectos da valorização do magistério.

Até então, essa perspectiva permanecia como importante agenda política no horizonte reivindicada pelas organizações sindicais dos educadores, mas, sobretudo, como mera retórica nos discursos dos governantes, apesar da sua inscrição mais evidente no texto constitucional, como Piso Salarial Profissional Nacional (PSPN), desde 1988 (BRASIL, 1988).

Inicialmente tímido, insuficiente e restrito a uma etapa da educação básica, a política de fundos exigiu a aplicação, por parte dos governos estaduais e municipais - principais responsáveis pelo atendimento de educação básica -, de um percentual mínimo na remuneração dos profissionais do magistério, o que motivou o interesse e a curiosidade acadêmica de pesquisadores e pesquisadoras pela/na investigação desse tema, transformado a partir de então em objeto de pesquisa.

A concretização da política trazia consigo a necessidade da transparência de informações e dados sobre a forma como os profissionais do magistério eram remunerados. O Fundef implicava em publicizar algum grau de detalhamento da contabilidade das receitas e, principalmente das despesas, uma vez que passou a ser matéria de controle de

\footnotetext{
"O presente trabalho foi realizado com apoio do Programa Observatório da Educação, da Coordenação de Aperfeiçoamento de Pessoal de Nível Superior - CAPES/Brasil". No âmbito desse programa e desse apoio imprescindível, foi realizada a Pesquisa Remuneração de Professores de Escolas Públicas de Educação Básica no contexto do Fundeb e PSPN, financiada pelo Edital n. 49/2012, CAPES/INEP/MEC, da qual decorrem muitos dos artigos aqui reunidos.
} 
acompanhamento social por conselhos instituídos especificamente para "fiscalizar" uma parcela da vinculação de receitas para a educação. A inscrição em lei trazia também a fiscalização dos órgãos de controle externo.

Apesar da grande expectativa criada pelo discurso governamental, os avanços foram tímidos ao longo do período em que o Fundef permaneceu em vigência, sequer existentes para alterar o quadro da baixa remuneração generalizada do magistério público brasileiro. A prioridade da gestão do governo federal a uma política macroeconômica e fiscal, profundamente austera, sustentada sobre pressupostos neoliberais, voltada ao ajuste e ao pagamento de elevados juros da dívida pública, não somente secundarizou a política educacional nesse campo como deixou de cumprir parte da legislação que poderia destinar recursos financeiros substanciais aos sistemas de ensino estaduais e municipais mais precários da federação brasileira e assim favorecer a melhoria da remuneração dos professores desses sistemas.

Ainda que a política macroeconômica não tenha sido abandonada com a gestão do governo federal, iniciada em 2003, os compromissos políticos assumidos com parcelas de trabalhadores organizados, como foi o caso com os professores da educação básica, colocou a política educacional sob uma perspectiva socialmente bem mais relevante.

Assim, a aprovação do Fundo de Manutenção e Desenvolvimento da Educação Básica e de Valorização dos Profissionais da Educação (Fundeb), em 2006, (BRASIL, 2006; 2007), além de resgatar a educação básica como um direito (PINTO, 2007), estabeleceu o vínculo jurídico-legal para a aprovação de uma Lei que instituísse um PSPN, o qual, contudo, só veio a ser objeto de aprovação, pelo Poder Legislativo Federal, em 2008 (BRASIL, 2008). O PSPN, instituído incialmente com o valor de $\mathrm{R} \$ 950,00$ para o professor de educação básica formado em nível médio e com jornada de trabalho de 40 horas semanais, garantiu também um dispositivo de reajustes anuais com índices acima da inflação do período. Uma outra histórica e importante reivindicação da categoria foi contemplada, qual seja, uma proporção de, ao menos, $1 / 3$ da jornada de trabalho sem a presença de educandos. Entretanto, novos embates e dilemas se colocaram no horizonte para fazer valer as conquistas e os direitos integrais da mencionada Lei.

Governadores estaduais ${ }^{2}$ imediatamente frearam os direitos de valorização da categoria do magistério da educação básica com a impetração de uma Ação Direta de Inconstitucionalidade (ADIn) sobre a Lei 11.738/2008 (BRASIL, 2008), junto ao Supremo Tribunal Federal, alegando quebra de autonomia federativa por parte da União. Tal questão transformou-se em contenda federativa (FERNANDES; RODRIGUEZ, 2011), que somente foi resolvida em 2011 com ganho de causa para a União. Enquanto isso se arrastou, de 2008 a 2011, o cumprimento e a implementação da lei do PSPN para os professores da educação básica ficou em suspenso, salvo negociações locais entre governos e movimento sindical docente.

Diante de ações como essa, a questão do PSPN, mesmo inscrito em lei, permanece na agenda de luta dos professores da educação básica, pois pode-se observar que, ainda em

2 Foram os Governadores dos seguintes estados: Rio Grande do Sul, Santa Catarina, Paraná, Mato Grosso do Sul e Ceará, os quais contaram com o apoio dos governadores dos estados de São Paulo, Minas Gerais, Tocantins e do Distrito Federal. 
Remuneração de Professores da Educação Básica em Tempos de FUNDEB, PSPN e PNE 2014-2024

2019, a Lei não vem sendo rigorosamente cumprida, tanto por estados como por municípios (CNTE, 2019).

Em 2014, com a aprovação da Lei n. 13.005, que instituiu o Plano Nacional de Educação (PNE 2014-2024) (BRASIL, 2014), nova possibilidade de valorização docente por meio remuneratório se aventou. Com efeito, a Meta 17 do PNE 2014-2024 dispôs a equiparação salarial do professor aos demais trabalhadores com formação e jornada de trabalho equivalentes.

Mas, ainda hoje, no contexto em que apresentamos este dossiê, 30 anos após a inscrição constitucional do princípio da valorização do magistério, constatamos com a Confederação Nacional dos Trabalhadores em Educação (CNTE) a presença de "[...] professoras e professores brasileiros com renda $40 \%$ menor em média em relação a outro profissional com mesma formação" (CNTE, 2019, p. 01).

O ciclo de indução da União para que as unidades federativas assumissem a valorização docente por meio remuneratório se encerrou em 2016 por ocasião do processo de impedimento sofrido pela Presidenta da República, Dilma Vana Rousseff. A conjuntura que se processa desde então, ainda que a valorização docente por meio remuneratório não tenha escapado da legislação, é, pelo contrário, totalmente desfavorável aos professores.

Assim, o ciclo de indução que exigiu esforços das unidades federadas para que estas se comprometessem com a busca de valorização dos professores da educação básica parece ter se encerrado com a aprovação da Emenda Constitucional n. 95/2016 (BRASIL, 2016). Novamente, o centro da política macroeconômica retorna agora com um grau de austeridade jamais visto, com o congelamento de gasto público federal pelo período de 20 anos, ao qual as unidades federativas têm se ajustado promovendo ajustes fiscais com arrochos salariais até o limite de quebra total de contrato social, e impondo, em muitos casos, atrasos nos pagamentos de salários aos servidores públicos, em geral, e aos docentes, em particular.

Outrossim, o ano de 2018 também foi marcado por nova conjuntura a partir da eleição presidencial. Certamente, o novo governo que chegou ao Planalto Central está comprometido com forças sociais que objetivam exclusivamente a acumulação ampliada do capital e a restauração do poder de classe (HARVEY, 2008). Para atacar a contrarreforma em curso, portanto, o grau de organicidade da classe trabalhadora será o grande desafio do período.

Com efeito, a escalada de intensificação dos ataques à classe trabalhadora, que vinha sendo gestado por grupos sociais nos anos 2000 e 2010, após o golpe de Estado em 2016 e com a eleição de um governo da extrema direita política em 2018, ganha status de política social. Os ataques não vêm, evidente, se materializando somente na precarização das condições materiais de existências da classe trabalhadora. Particularmente para os docentes, também tem se colocado um grande ataque no plano político ideológico, com vistas a reprimir, responsabilizar e criminalizar o trabalho docente.

Por tudo isso, entendemos que a leitura dos artigos selecionados para este dossiê tornase fundamental. Os artigos registram o movimento da remuneração como expressão de possível valorização docente em momento imediatamente anterior ao da conjuntura atual, quando, ao mesmo tempo, em alguns deles já se pode antever tendências que agora estão a se materializar e que exigirão do conjunto da classe trabalhadora grande esforço de organicidade para que os direitos sociais sejam corrompidos em menor grau. 
Remuneração de Professores da Educação Básica em Tempos de FUNDEB, PSPN e PNE 2014-2024

Diante disso, desejamos a todos uma boa leitura deste registro e que o conjunto aqui apresentado sirva de instrumental tanto para uma nova agenda de pesquisa quanto para a luta em curso, tão necessárias!

\section{Referências}

BRASIL. (Constituição 1988). Constituição da República Federativa do Brasil de 1988. Diário Oficial da União, Brasília, 1988.

BRASIL. Lei n ${ }^{\circ} 9.424$, de 24 de dezembro de 1996. Dispõe sobre o Fundo de Manutenção e Desenvolvimento do Ensino Fundamental e de Valorização do Magistério, na forma prevista no art. $60, \S 7^{\circ}$, do Ato das Disposições Constitucionais Transitórias, e dá outras providências. Diário Oficial da União, Brasília, 1996. Disponível em: <http://www.planalto.gov.br/ ccivil_03/LEIS/L9424.htm>. Acesso em: 3 jan. 2019.

BRASIL. Emenda Constitucional $n^{\circ} 53$, de 19 de dezembro de 2006. Dá nova redação aos arts. $7^{\circ}, 23,30,206,208,211$ e 212 da Constituição Federal e ao art. 60 do Ato das Disposições Constitucionais Transitórias. Diário Oficial da União, Brasília, 2006. Disponível em: <http://www.planalto.gov.br/ccivil_03/Constituicao/Emendas/Emc/emc53.htm>. Acesso em: 16 mar. 2019.

BRASIL. Lei $n^{\circ} 11.494$, de 20 de junho de 2007. Regulamenta o Fundo de Manutenção e Desenvolvimento da Educação Básica e de Valorização dos Profissionais da Educação FUNDEB, de que trata o art. 60 do Ato das Disposições Constitucionais Transitórias; altera a Lei no 10.195, de 14 de fevereiro de 2001; revoga dispositivos das Leis nos 9.424, de 24 de dezembro de 1996, 10.880, de 9 de junho de 2004, e 10.845, de 5 de março de 2004; e dá outras providências. Diário Oficial da União, Brasília, 2007. Disponível em: <http://www.planalto.gov.br/ccivil_03/_Ato2007-2010/2007/Lei/L11494.htm>. Acesso em: 7 jan. 2019.

BRASIL. Lei n 11.738, de 16 de julho de 2008. Regulamenta a alínea "e" do inciso III do caput do art. 60 do Ato das Disposições Constitucionais Transitórias, para instituir o piso salarial profissional nacional para os profissionais do magistério público da educação básica. Diário Oficial da União, Brasília, 2008. Disponível em: <http://www.planalto.gov.br/ccivil_03/ _Ato2007-2010/2008/Lei/L11738.htm>. Acesso em: 8 fev. 2019.

BRASIL. Lei n 13.005, de 25 de junho de 2014. Aprova o Plano Nacional de Educação - PNE e dá outras providências. Diário Oficial da União, Brasília, 2014. Disponível em: <http://www.planalto.gov.br/ccivil_03/_Ato2011-2014/2014/Lei/L13005.htm>. Acesso em: 8 jan. 2019.

BRASIL. Emenda Constitucional $n^{\circ}$ 95, de 15 de dezembro de 2016. Altera o Ato das Disposições Constitucionais Transitórias, para instituir o Novo Regime Fiscal, e dá outras providências. Diário Oficial da União, Brasília, 2016. Disponível em: <http://www.planalto. gov.br/ccivil_03/Constituicao/Emendas/Emc/emc95.htm>. Acesso em: 9 fev. 2019.

CNTE. Confederação Nacional dos Trabalhadores em Educação. Reajuste do piso do Magistério é menor que o do salário mínimo e do Judiciário. Brasília, 2019. Disponível em: <http://www.cnte.org.br/index.php/cnte-na-midia/20472-reajuste-do-piso-do-magisterioe-menor-que-o-do-salario-minimo-e-do-judiciario.html>. Acesso em: 8 fev. 2019. 
Remuneração de Professores da Educação Básica em Tempos de FUNDEB, PSPN e PNE 2014-2024

FERNANDES, Maria Dilnéia Espíndola; RODRIGUEZ, Margarita Victoria. O processo de elaboração da Lei n. 11.738/2008 (Lei do Piso Salarial Profissional Nacional para carreira e remuneração docente): trajetória, disputas e tensões. Revista HISTEDBR, Campinas, n. 41, p. 88-101, mar. 2011.

HARVEY, David. O neoliberalismo - história e implicações. São Paulo: Edições Loyola, 2008.

PINTO, José Marcelino de Rezende. A política recente de fundos para o financiamento da educação e seus efeitos no pacto federativo. Educação \& Sociedade, Campinas, v. 28, n. 100 , p. $877-897$, out. 2007. Disponível em: <http://www.scielo.br/scielo.php?script=sci_ arttext\&pid=S0101-73302007000300012\&lng=pt\&nrm=iso>. Acesso em: 16 mar. 2019.

Marcos Edgar Bassi é professor da Universidade Federal de Santa Catarina (UFSC), credenciado ao Programa de Pós-Graduação em Educação/UFSC. Tem desenvolvido pesquisa nos temas da política educacional e do financiamento da educação. Bacharel em Ciências Econômicas pela Universidade Municipal de São Caetano do Sul (IMES). Mestrado e Doutorado realizados no Programa de Estudos Pós-Graduados em Educação: História, Política, Sociedade, da Pontifícia Universidade Católica de São Paulo (PUC-SP). Estágio PósDoutoral realizado na Faculdade de Educação da Universidade de São Paulo (FEUSP).

ORCID: http://orcid.org/0000-0002-4556-2969

E-mail: marcos.e.bassi@gmail.com

Maria Dilnéia Espíndola Fernandes é doutora em Educação, professora da Universidade Federal de Mato Grosso do Sul (UFMS), Campo Grande/MS - Brasil.

ORCID: http://orcid.org/0000-0001-5218-8541

E-mail: mdilneia@uol.com.br

Rosana Maria Gemaque Rolim é professora Dr. a da Faculdade de Educação da Universidade Federal do Pará. Pesquisadora da área de financiamento da educação básica e remuneração de professores da educação básica.

ORCID: http://orcid.org/0000-0002-6475-0172

E-mail: rgemaque@uol.com.br 


\section{Editores do volume 9}

José Marcelino de Rezende Pinto - Universidade de São Paulo, São Paulo/SP, Brasil

Nalú Farenzena - Universidade Federal do Rio Grande do Sul, Porto Alegre/RS, Brasil

\section{Comitê Editorial}

José Marcelino de Rezende Pinto - Universidade de São Paulo, Brasil

Juca Gil - Universidade Federal do Rio Grande do Sul, Brasil

Theresa Adrião - Universidade Estadual de Campinas, Brasil Ângelo

Ricardo de Souza - Universidade Federal do Paraná, Brasil

Márcia Aparecida Jacomini - Universidade Federal de São Paulo, Brasil

\section{Conselho Editorial}

\section{Alejandro Morduchowicz}

Universidad Pedagógica, Provincia de Buenos Aires, Argentina

Fernanda Saforcada

Universidade de Buenos Aires, Argentina

Jacques Velloso

Universidade de Brasília, Brasil

João Monlevade

Senado Federal, Brasil

Jorge Abrahão de Castro

Instituto de Pesquisa Econômica Aplicada / IPEA, Brasil

Juca Gil

Universidade Federal do Rio Grande do Sul, Brasil

Lisete Regina Gomes Arelaro

Universidade de São Paulo, Brasil

Luis Carlos Sales

Universidade Federal do Piauí, Brasil

Luiz de Sousa Junior

Universidade Federal da Paraíba, Brasil

Luiz Fernandes Dourado

Universidade Federal de Goiás, Brasil

Magna França

Universidade Federal do Rio Grande do Norte, Brasil

\section{Maria Beatriz Luce}

Universidade Federal do Pampa, Brasil

Universidade Federal do Rio Grande do Sul, Brasil

Marcos Edgar Bassi

Universidade Federal de Santa Catarina, Brasil

\author{
Maria Dilnéia Espíndola Fernandes \\ Universidade Federal de Mato Grosso do Sul, Brasil \\ Nalú Farenzena \\ Universidade Federal do Rio Grande do Sul, Brasil \\ Nelson Cardoso do Amaral \\ Universidade Federal de Goiás, Brasil \\ Nicholas Davies \\ Universidade Federal Fluminense, Brasil \\ Rosana Evangelista Cruz \\ Universidade Federal do Piauí, Brasil \\ Rosana Gemaque \\ Universidade Federal do Pará, Brasil \\ Robert E. Verhine \\ Universidade Federal da Bahia, Brasil \\ Romualdo Portela de Oliveira \\ Universidade de São Paulo, Brasil \\ Theresa Adrião \\ Universidade Estadual de Campinas, Brasil \\ Tristan McCowan \\ University of London, Reino Unido \\ Vera Jacob \\ Universidade Federal do Pará, Brasil \\ Vera Peroni \\ Universidade Federal do Rio Grande do Sul, Brasil \\ Vitor Henrique Paro \\ Universidade de São Paulo, Brasil
}

\section{Equipe editorial}

Apoio ao Comitê Editorial: Patrícia Balthazar Garcia

Diagramação, Revisão de português e normalização: Edson Leonel de Oliveira

Revisão de inglês: Ananyr Porto Fajardo 